\title{
Stress Concentration Factors for Multi-planar Tubular Joints Subjected to Axial Loading
}

\author{
Kai Zhou ${ }^{1}$, Jingjing Zuo ${ }^{1}$, Wenhua Wang ${ }^{2, *}$, Shiliu Bao ${ }^{2}$ \\ ${ }^{1}$ Powerchina Zhongnan Engineering Corporation Limited, Changsha, China \\ ${ }^{2}$ State Key Laboratory of Coastal and Offshore Engineering Department, Dalian University of Technology, Dalian, China
}

\begin{abstract}
The support structure for an offshore wind turbine is subjected to combined hydrodynamic loads and aerodynamic loads. The tubular joints are the weakest component leading to fatigue failure of the whole structure. Based on the multi-pile foundation structure which is used widely in China, the typical threeplanar tubular Y-joints is selected to study stress concentration factor (SCF). Then, the load types subjected to axial loadings of three-planar tubular Y-joints are determined. The finite element models of three-planar tubular Y-joints are established and used to calculate hot spot stresses. The stress concentration factors along the weld of the three-planar tubular Y-joints under the axial forces are obtained. The effects of geometrical parameters on SCFs are studied.
\end{abstract}

\section{Introduction}

Offshore wind power development is rapidly growing to satisfy the demand for sustainable energy. Fatigue is a significant factor resulting in the failure of the support structure of offshore wind turbines subjected to combined aerodynamic and hydrodynamic loadings. Multi-pod piled substructure is widely used in China, as shown in Fig. 1. The connection between diagonal braces and the central column as the major loadbearing components is defined as the multi-planar Y tubular joint. The weld itself and geometrical discontinuity around the tubular joint cause stress concentration, which is a detrimental impact on the fatigue performance of offshore structures.

The fatigue design is based on S-N curves, which are obtained from fatigue tests. In S-N curves, the number of cycles that a tubular joint can sustain before a fatigue failure is determined by the hot spot stress range. The stress concentration due to the weld itself is included in the S-N curve used, while the stress concentration due to the geometry effect of the actual detail is determined by means of calculation of hot spot stress. Generally, the hot spot stress is calculated by multiplying the nominal stress by the stress concentration factor (SCF). The determination of SCF has been an issue for tubular structures in the past decades. At present, there are many published parametric SCF equations for tubular joints subjected to different basic loadings. The SCFs for simple tubular joints are listed in the fatigue design codes such as API[1] and DNV-RP-C203[2]. Hot spot stresses at failure-critical locations for four types of multi-planar tubular joints such as DK, DKT, X-type are derived, and the effects of planar and non-planar braces are considered by Dong[3]. Woghiren[4] carried out a parametric stress analysis of the various configuration of rack plate stiffened multi-planar KK-joints. Considering the bending effect, Karamanos[5] computed SCFs of DTjoint. Ahmadi[6] proposed a set of parametric SCFs equations for the three-planar KT-joint under three axial loading conditions.

Using solid elements, the finite element models of three-planar Y-joints, as shown in Fig. 2, are established. The stress concentration factors along the weld of the three-planar tubular Y-joints under the axial loads are obtained. The effects of geometrical parameters on SCFs are studied.

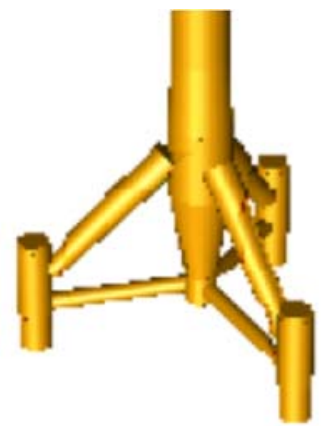

Fig. 1. The substructure of offshore wind turbine

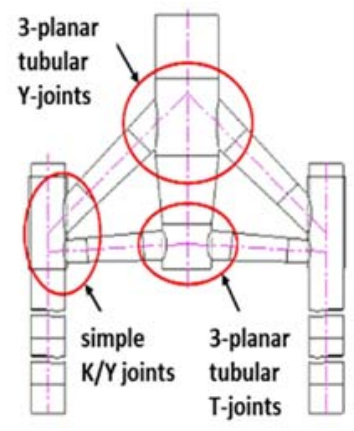

Fig. 2. Schematic diagram of tubular joints.

\section{Finite element model}

\subsection{Calculation method}

The peak stress is calculated by extrapolating the geometrical stresses at the two points to the weld toe position in a linear way. According to DNV-RP-C203[2], the minimum and maximum distances from the two points to the weld toe for chord members are defined in

\footnotetext{
*whwanghydro@dlut.edu.cn
} 
Fig. 3 and Table 1. Then, the SCF distribution along the weld toe for each plane can be obtained.

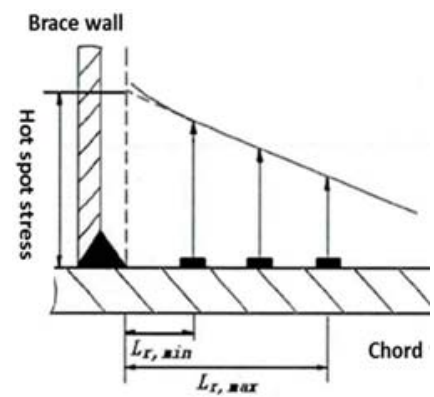

Tab. 1 Extrapolation points location

\begin{tabular}{ccc}
\hline $\begin{array}{c}\text { Locati } \\
\text { on }\end{array}$ & Chord & Brace \\
\hline$L_{r, \min }$ & $0.2(D T / 2)^{0.5}$ & $\begin{array}{c}0.2(d t / 2)^{0 .} \\
5\end{array}$ \\
$L_{r, \max }$ & $\begin{array}{c}0.4(d t D T / 4) \\
0.25\end{array}$ & $\begin{array}{c}0.65(d t / 2) \\
0.5\end{array}$ \\
\hline
\end{tabular}

Fig. 3. Interpolation region

\subsection{Selection of geometrical parameters}

The joint is connected with three diagonal braces, and a central column forms a three-planar tubular joint with an angle of $120^{\circ}$ among the diagonal braces by horizontal projection. The numbering of the diagonal braces for three-planar tubular Y-joints is displayed in Fig. 4. From the extensive studies by the researchers, the geometrical parameters that affect the SCFs of tubular joints include the ratio of chord length to chord radius, $\alpha$, the ratio of brace diameter to chord diameter, $\beta$, the ratio of chord radius to chord wall thickness, $\gamma$, the ratio of brace wall thickness to chord wall thickness, $\tau$, the angle between the chord axis and brace axis, $\theta$, and the angle among diagonal braces, $\varphi$.

\subsection{Finite element modeling}

Finite element (FE) modeling of the weld profile is the most critical factor affecting the accuracy of SCF results. In the study, the welding size along the brace/chord intersection satisfies the AWS D1.1 specification [7].

Using ANSYS, the SOLID45 element type is used in the study to model three-planar Y-joints composed of the chord, braces, and weld profiles. Using three dimensional solid elements will obtain more accurate and detailed stress distribution near the intersection in comparison with a shell element. The material is steel with elastic modulus, $\mathrm{E}=207 \mathrm{GPa}$, Poisson's ratio is 0.3 .

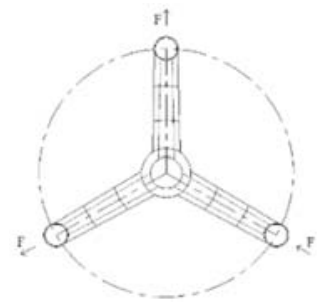

(a) LT1

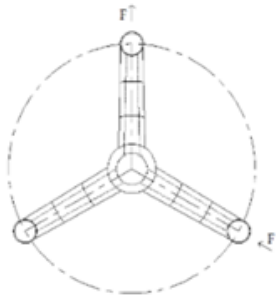

(b) LT2

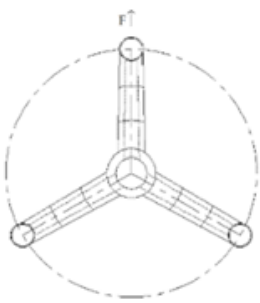

(c) LT3

Fig. 6. Axial loadings cases of three-planar tubular Y-joints

To guarantee the mesh quality, a sub-zone mesh generation method is used during the FE modeling. In this method, the entire joint is divided into several zones according to the computational requirements. This method can easily control the mesh quantity and quality to avoid badly distorted elements.

To verify the convergence of FE results, a convergence test with different mesh densities is conducted. The number of elements for both thickness of the chord and thickness of the brace is 3.90 elements are used along the curve of the weld toe. The FE models of three-planar tubular Y-joints are displayed in Fig.5.

Both chord ends are assumed to be fixed; thus, the three translational degrees of freedom such as $\mathrm{Ux}, \mathrm{Uy}$, and $\mathrm{Uz}$ corresponding to end nodes are restrained. The axial loading is applied to the brace end sections according to different axial loading cases.

Fig. 4. The numbering of diagonal braces

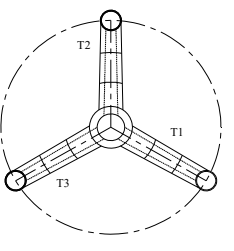

2.4. Determination of loading cases

Using SACS, some practical structures of offshore wind turbines with tripod substructures subjected to the aerodynamic and hydrodynamic loadings for fatigue limit state are analyzed. From the results, the loading cases for three-planar Y-joints under axial loadings are determined and shown in Fig. 6.

\section{Distribution of SCFs along the weld toe}

For three-planar Y-joints composed of the three simple $\mathrm{Y}$-joint, the numbering of the diagonal braces shown in Fig. 4 is used to represent each uni-planar Y-joint. The definition of polar angle $\varphi$ along the weld's spatial curve for each simple Y-joint is shown in Fig. 7.

\subsection{LT1 results}

The SCFs distributions along the weld toe of each simple Y-joint subjected to load case LT1 are displayed in Fig. 8. The location of maximum SCF is not at but close to the saddle of the weld toe due to the interaction between three simple Y-joint. For LT1, the applied axial loadings are symmetrical to the plane from the diagonal brace T1 and the central column. Thus, the SCFs distribution of Y- 
joint T1 is symmetrical to the crown of the weld in chord and brace. Although the SCFs distributions for Y-joint $\mathrm{T} 2$ and $\mathrm{T} 3$ are unsymmetrical to the weld crown, the trend of SCFs distribution for Y-joint T2 is the opposite

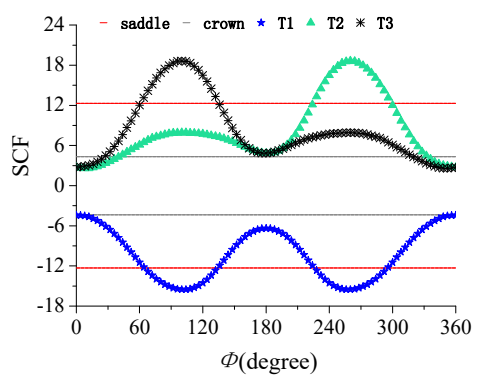

(a) chord of that for Y-joint T3. The maximum SCF for Y-joint T2 occurs in $\varphi=260^{\circ}$, but that for $\mathrm{Y}$-joint T3 in $\varphi=100^{\circ}$. Due to the interaction between T2 and T3, the maximum SCFs from T2 and T3 are larger than those from T1.

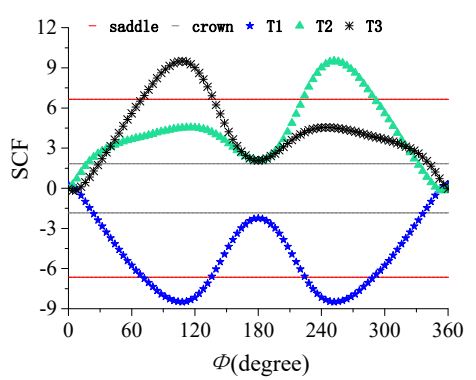

(b) brace

Fig. 8. SCF distribution for load case LT1

\subsection{LT2 results}

The SCFs distributions along the weld toe of each simple Y-joint subjected to load case LT2 are displayed in Fig. 9. The location of the maximum SCF is not at but close to the saddle of the weld toe. For LT2, the applied axial loadings are unsymmetrical to any plane from each diagonal brace and the central column. Thus, the SCFs distribution of each simple $\mathrm{Y}$-joint is unsymmetrical to

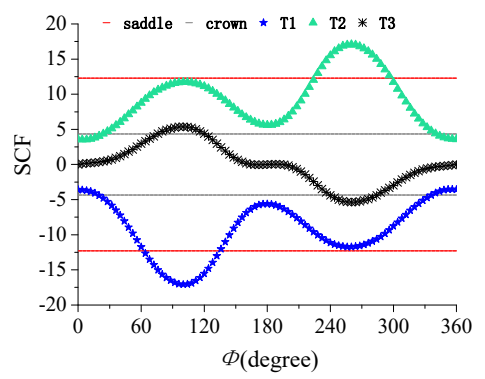

(a) chord

the crown of the weld in chord and brace. Although the SCFs distributions for Y-joint $\mathrm{T} 1$ and $\mathrm{T} 2$ are unsymmetrical to the weld crown, the trend of SCFs distribution for $\mathrm{Y}$-joint $\mathrm{T} 1$ is the opposite of that for $\mathrm{Y}$ joint T2. The maximum SCF for Y-joint T1 occurs in $\varphi=$ $100^{\circ}$, but that for $\mathrm{Y}$-joint $\mathrm{T} 2$ in $\varphi=260^{\circ}$. Due to the interaction between $\mathrm{T} 1$ and $\mathrm{T} 2$, the maximum SCFs from $\mathrm{T} 1$ and $\mathrm{T} 2$ are larger than those from $\mathrm{T} 3$.

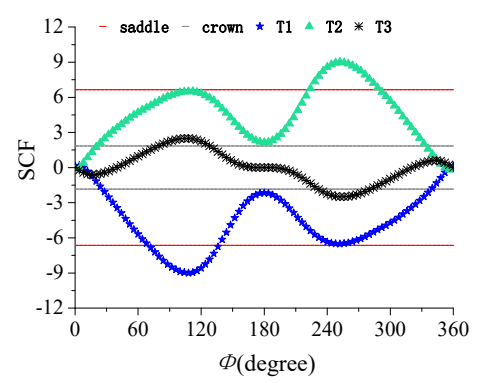

(b) brace

Fig. 9. SCF distribution for load case LT2

\subsection{LT3 results}

The SCFs distributions along the weld toe of each simple Y-joint subjected to load case LT3 are displayed in Fig. 10. The maximum SCF locates in the saddle of the weld toe for Y-joints subjected to axial loadings. For LT3, the applied axial loadings are symmetrical to the plane from the diagonal brace T2 and the central column. Thus, the SCFs distribution of Y-joint T2 is symmetrical to the

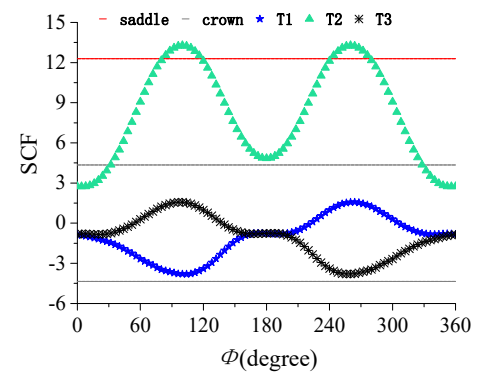

(a) chord crown of the weld in chord and brace. Although the SCFs distributions for $\mathrm{Y}$-joint $\mathrm{T} 1$ and $\mathrm{T} 3$ are unsymmetrical to the weld crown, the trend of SCFs distribution for $\mathrm{Y}$-joint $\mathrm{T} 1$ is the opposite of that for $\mathrm{Y}$ joint T3. The maximum SCF for Y-joint T1 occurs in $\varphi=$ $104^{\circ}$, but that for $\mathrm{Y}$-joint $\mathrm{T} 3$ in $\varphi=256^{\circ}$. Due to the interaction between $\mathrm{T} 1$ and $\mathrm{T} 3$, the maximum SCFs from $\mathrm{T} 1$ and $\mathrm{T} 3$ are smaller than those from $\mathrm{T} 2$.

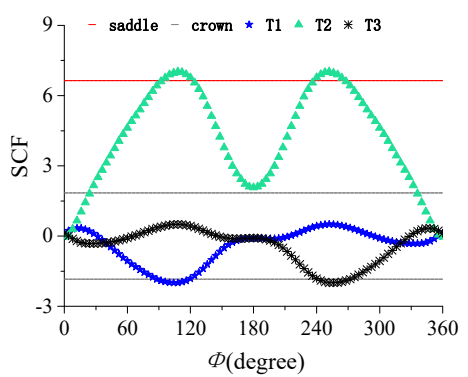

(b) brace

Fig. 10. SCF distribution for load case LT3 


\section{Geometrical effects on the SCFs}

Using FE simulation, the effects of geometrical parameters on the SCFs of three-planar tubular Y-joints subjected to axial loadings are analyzed. The following conclusions can be drawn.

(1) For three-planar tubular Y-joints subjected to axial loadings, SCFs in the chord are larger than those in braces. SCFs are maximum when all the diagonal braces are applied to axial loadings, indicating that the interaction among each simple $\mathrm{Y}$-joints occurs.

(2) For three-planar tubular Y-joints subjected to axial loadings, the geometric parameters, i.e., $\alpha, \beta, \gamma, \tau, \theta$, and $\varphi$, have a significant influence on SCFs.

(3) For the SCFs in chord and braces under the condition that all diagonal braces are applied to axial loadings, the results from DNV suitable for simple Yjoint are smaller than FE results. Thus, if the SCFs in chord from DNV is used to carry out fatigue checks of multi-planar tubular Y-joints, the assessment will not be conservative.

\section{Acknowledgement}

This research was supported by the National Natural Science Foundation of China (Grant No. 52001052).

\section{References}

1. API. Recommended Practice for Planning, Designing, and Constructing Fixed Offshore Platforms - Load and Resistance Factor Design. 1997.

2. DNV-RP-C203. Fatigue Design of Offshore Steel Structures. 2011.

3. Dong WB, Moan T, Gao Z. Long-term fatigue analysis of multi-planar tubular joints for jackettype offshore wind turbine in time domain. Engineering Structures, 2011, 33: 2001-2014.

4. Woghiren $\mathrm{C} \mathrm{O}$, Brennan F P. Weld toe stress concentrations in multi-planar stiffened tubular KK joints. International Journal of Fatigue. 2009, 31(1): 164-172.

5. Karamanos S A, Romeijn A, Wardenier J. SCF equations in multi-planar welded tubular DTjoints including bending effects. Marine structures. 2002, 15(2): 157-173.

6. Ahmadi H, Mohammad A L, Mohammad H A. The development of fatigue design formulas for the outer brace SCFs in offshore three-planar tubular KT-joints. Thin-Walled Structures, 2012, 58(67-78).

7. American Welding Society (AWS). Structural Welding Code, AWS D1.1. Miami, USA, 2009. 